\title{
High Efficiency Device to Cut Gases Emissions from Mobile Sources
}

\author{
Raúl Guerrero Torres \\ Universidad de Cartagena \\ Piedra de Bolívar, Ave. del Consulado, Cll. 30 \#39 B-192 \\ Cartagena de Indias Colombia \\ rguerrerotores1@unicartagena.edu.co
}

\begin{abstract}
The main goal of this paper is to report emission tests results achieved with the Power Pack ${ }^{\mathrm{TM}}$, an Increasing Oxygen device for enhancing fuel efficiency of internal combustion engines in mobile sources, fabricated in U.S.A by H\&G Fluid Stabilization Technology and evaluated in Colombia under the sponsorship of DEL LTDA. The Power Pack ${ }^{\mathrm{TM}}$ is installed properly on the fuel supply line. When the fuel flows through its internal parts where it exposes to two neodymium magnets, negative charges are transferred through a grounded wire and becomes positively charged. Then, when the fuel mixes with the air, near complete combustion is obtained. Five cars and five motorcycles were tested without and with the device installed to analyse emissions variations. Two types of tests were made: Single Day Tests; two tests, for all the vehicles, with and without the device installed, and Periodical Tests; with the device installed, for chosen vehicles, in different days, to check emissions variations over time. Carbon monoxide and hydrocarbons emissions results were obtained from gas analysers of two Automotive Diagnostic Centers in the city of Cartagena, Colombia. When results of Single Day Tests for cars were analysed, remarkable average emissions reductions of $75 \%$ in $\mathrm{HC}$ and $71.73 \%$ in CO were obtained. For motorcycles, remarkable average emissions reductions of $74.32 \%$ in $\mathrm{HC}$ and $75.38 \%$ in $\mathrm{CO}$ were obtained. From Periodical Tests results for the studied car, final emissions reductions of $57.30 \%$ in $\mathrm{HC}$ and $27.71 \%$ in $\mathrm{CO}$ were obtained. For the first studied motorcycle final emissions reductions of $28.65 \%$ in $\mathrm{HC}$ and $41.53 \%$ in CO were obtained. For the second studied motorcycle final emissions reductions of $72 \%$ in $\mathrm{HC}$ and $15.92 \%$ in $\mathrm{CO}$ were obtained. All the vehicles fulfilled the Colombian norms after having the PPTM installed.
\end{abstract}

Keywords: ADC, IC engines, Mobile Sources emissions, Fuel Efficiency optimizer

\section{Introduction}

International experts have been declaring emphatically, at least in the last two lustra that in spite of reduction of air pollution in some big cities, as Mexico City, once the more polluted city of the planet, and Los Angeles, as two noticeable examples, global air pollution that could be lethal, has been worsening remarkably in many cities of the world, especially in the big cities of Asia and Latin America, in the last decades. This declaration supported on real facts allows to state that non of all the factors in favour of fighting together against air pollution should be discarded; None of this factors alone has been able to solve the global air pollution of our planet. One of this factors is the use of fuel efficiency optimizers as the efficient one whose results we present in this paper.

Here some trends, reinforcing the aforesaid statement, found from 2006-2016:

2006-2007

There are clear signals that Air pollution in Latin America not has worsened. Examples of Colombia are presented as follows: according to the Institute of Hydrology Environmental Meteorology and Studies (Ideam) data and the Department of Geography of the National University of Colombia, the temperature of the air increased between 0.1 and $0.2{ }^{\circ} \mathrm{C}$ per decade during the second half of the XX century (Roatta Acevedo Carolina, 2007); reduction of snow covered areas. Every year, these zones lose between $2 \%$ and $3 \%$ of their surface; in the Colombian coasts, for example there is a registered tendency the mean sea level to increase, annually, in three to four millimetres in Pacific and in one to two millimetres in the Caribbean; The frequency of rains also have increased or decreased in some regions; Numbers reveal that $41 \%$ of air pollution of the country is concentrated in Bucaramanga, Bogotá, Medellin, Cali, Barranquilla, Cartagena, Pereira and the Sogamoso valley and $86 \%$ of this air pollution is caused by mobile sources. (Environment, Housing and Development Ministry, 2006). 


\section{8-2013}

1. In the World Meteorological Day eve (March 23 of 2009) World Health Organization esteemed that 2 million people die prematurely every year because of air pollution and also because of this cause, other many undergo breathing diseases, cardiopathies, pulmonary infections and even cancer. In Asia, many cities like Karachi, New Delhi, Kathmandu, Dacca, Shanghai, Beijing and Bombay exceed all the limits", said to the press. "Also several cities of South-America as Lima, Santiago or Bogotá", added.

2. Global urban air pollution levels increased by $8 \%$, despite improvements in some regions.

3. In general, urban air pollution levels were lowest in high-income countries, with lower levels most prevalent in Europe, the Americas, and the Western Pacific Region.

4. The highest urban air pollution levels were experienced in low-and middle-income countries in WHO's Eastern Mediterranean and South-East Asia Regions, with annual mean levels often exceeding 5-10 times WHO limits, followed by low-income cities in the Western Pacific Region.

5. In the Eastern Mediterranean and South-East Asia Regions and low-income countries in the Western Pacific Region, levels of urban air pollution have increased by more than 5\% in more than two-thirds of the cities.

6. In the African Region urban air pollution data remains very sparse, however available data revealed particulate matter (PM) levels above the median. The database now contains PM measurements for more than twice as many cities than previous versions.

\section{4-2016}

1. WHO | World Health Organization 7 million premature deaths annually linked to air pollution. (2014 March 25) Guardian More people die from air pollution than Malaria and HIV/Aids, new study shows (2015, September 16)

2. WHO | World Health Organization (2016, May 12) Air pollution levels rising in many of the world's poorest cities

3. Almost everyone on Earth now breathes polluted air, according to an air quality map released by the World Health Organization. (2016, September 28)

In spite of the implementation to great scale of emissions controllers (catalytic converters), air/fuel mixture trimmers (Oxygen Sensors) and all type of devices to reduce the emissions of mobile sources, million tons of harmful gases whose concentrations make them lethal for the health are still being sent to the atmosphere. As an example worth to be mentioned is the case of Mexico City, where restrictive measures in the entrance of used vehicles, retirement of the circulation of highly polluting vehicles, reduction to $50 \%$ of public institution vehicles circulation, systems of transport modernization, obligatory use of catalytic converters, use of anti-pollution devices, among other measures implemented in 4 years, only have been able to cut only a $10 \%$ the total mass of polluting emissions. That is to say, near 5 to 4,5 million tons of pollutants with an investment of 250 million dollars.

A very hard effort has been done in many countries to controlling air pollution. Among others Restrictive measures, better plans of vehicles circulation, better fuels selection, obligatory use of catalytic converters and others devices has helped a lot to reduce air pollution. Due to these devices million tons of polluting agents have not been released to the atmosphere but, no device is so highly efficient to solve completely the problem alone or in a synergic connection with others. Catalytic converters, for example though highly efficient, do not last forever and work efficiently only under very specific conditions and the same could be said for efficient fuel savers and fuel efficiency enhancers.

On the other hand, the increase of the automotive park in many countries is evident and the lack of renovation of the old one is it still more. This factors in synergy with the new kinds of mobile sources, among other factors, keeps on contributing enormously to worsen air pollution because they increase the contaminants in the air and make more difficult the solution of problem because the current anti-pollution devices are not often so efficient before the new mobile sources and consequently those are brought to discredit, not able to be in demand, able to discourage even the fabricators themselves and finally entail important reduction in number of devices to cut air polluting emissions. If we add to all these factors the limiting conditions of economical monopolies to a strictly scientific fabrication and continuous improvement control of the anti-pollution devices, we may conclude that there is too much work to do yet, in favour of air pollution control and that every effort in this via, even if is considered as a not great impact one, is important and can help "To Save the Planet".

Though we think that governments, at least, must make integral part of the design, fabrication and control of the use of anti-pollution devices, we recognize that there are many efficient devices and many strict controlling government institutions as CARB, for example but this is not enough because all the natural and anthropocentric changing conditions 
of our earth demand everyday more efficient anti-pollution devices. This article is mainly intended to present one of them, highly efficient; The Power Pack ${ }^{\text {TM }}$ an efficient device to cut gases emissions from mobile sources.

\section{The Device}

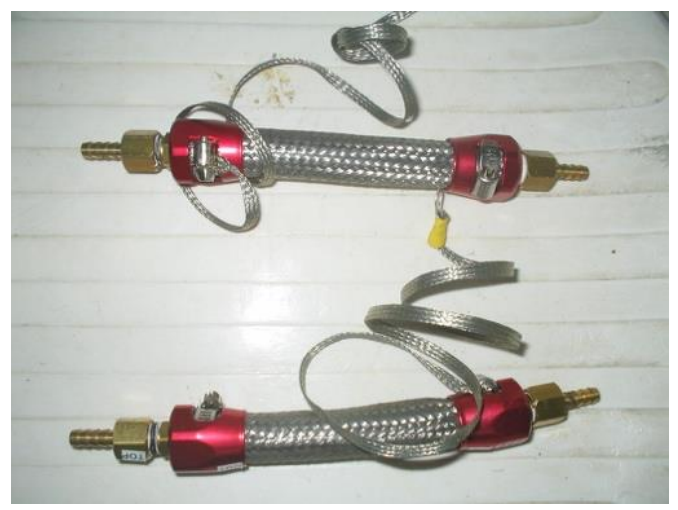

Fig. 1: Power Pack TM Units.

Designed and constructed in USA by Henry Guerrero, president of HG fluids, evaluated for more than 15 years in USA and finally, in the last years in Colombia, through an undergraduate Civil Engineering of University of Cartagena student's thesis, supervised by professor Edgar Quinones and sponsored technically and economically by DEL LTDA who has started the patent procedures. The Power Pack TM is an advanced electrostatic charger based not only on the breaking up of the fuel into droplets, when it flows through the alloy metal multidirectional flow device, that causes charges separations, but somehow in friction as many experiments have shown qualitatively, because quantitative determination of electrostatic charge build-up by friction is rarely possible, and Faraday's law of Induction. The Power Pack TM is installed, properly, inline on the fuel supply line. When the fuel flows through its internal parts and it exposes to two neodymium magnets, negative charges are transferred through a ground connected wire and becomes positively charged. When the fuel mixes with the air, near complete combustion is obtained. This results in: reduction in more than $50 \%$ in the hydrocarbons emissions. When traveling a 5-7 km distance after having the device installed; the hydrocarbons emissions are reduced to an approximated value of $50 \%$ or more. The reduction of the hydrocarbons emission decreases as time increases, becoming practically zero after traveling 1000 miles. When you are close to a 1000 miles' distance travelled with the device installed, oil and filter must be changed before making a new test. Because of the important improvement of combustion, the Power Pack ${ }^{\mathrm{TM}}$ increases the engine efficiency of the vehicle and also the fuel saving of the vehicle. Without movable pieces and minimum maintenance, it could be in the next future an indispensable piece of the equipment of a vehicle.

\section{General Objective}

The main goal of this paper is to report emissions tests results achieved with the power pack ${ }^{\mathrm{TM}}$, an IOFET. (Increasing Oxygen Fuel Enhancer Type) device for enhancing fuel efficiency of internal combustion engines in mobile sources.

\section{Measurements}

Five cars and five motorcycles were tested without the PРТM and at different times with the device installed to analyse emissions variations. Single Day Tests results for cars and motorcycles were also analysed. Carbon monoxide (CO) and hydrocarbons (HC) emissions results were obtained from gas analysers of two ADC (Automotive Diagnostic Centers) in the city of Cartagena which are governed by resolution 3500 of 2005 issued by the Ministry of Environment, Housing and Territorial Development, which sets minimum standards to make the technical-mechanical and gases diagnoses to different vehicles. 
Table 1: for analysed vehicles.

\begin{tabular}{|c|c|c|l|}
\hline TYPE & PLATES & MODEL & USE \\
\hline RENAULT SYMBOL & BRE 120 & 2005 & PRIVATE \\
\hline HYUNDAY & UAM 625 & 2006 & TAXI \\
\hline TOYOTA TERCEL & AUQ 225 & 1995 & PRIVATE \\
\hline HYUNDAY & BPL 234 & 2001 & PRIVATE \\
\hline SUSUKI (ZS) & PSF626 & 1979 & PRIVATE \\
\hline AUTECO BOXER & FDC 26D & 2005 & MOTOTAXI \\
\hline AUTECO BOXER & JIS 07B & 2008 & MOTOTAXI \\
\hline AUTECO BAJAJ & XIY 12A & 2001 & MOTOTAXI \\
\hline SUZUKI & XHL 36A & 1996 & MOTOTAXI \\
\hline SUZUKI & JIS 07B & 1997 & PRIVATE \\
\hline
\end{tabular}

\section{Tests}

Two types of tests were made: Periodical tests for chosen vehicles, in different days to check emissions variation with time and single day tests (two tests) for the rest of vehicles. The monitoring of the emissions was made by means of a conduction system in the exhaust pipe of the vehicles and the motorcycles. The system of pipes takes gases to a tester located inside the console of the gas analyser. This system has a filter that works like gas purifier.

\subsection{Periodical Tests}

These tests were made in a period of two months as follows:

Thirty minutes before installing the device.

After traveling five to seven kilometers, having the device installed

Seven days after the installation

Fifteen days after the installation

Thirty days after the installation

Forty-five days after the installation

Sixty days after the installation

\subsection{Single Day Tests}

For the two single day tests, one test was made without the Power Pack TM device installed and the second after traveling a distance of five to seven kilometres having the device installed. 


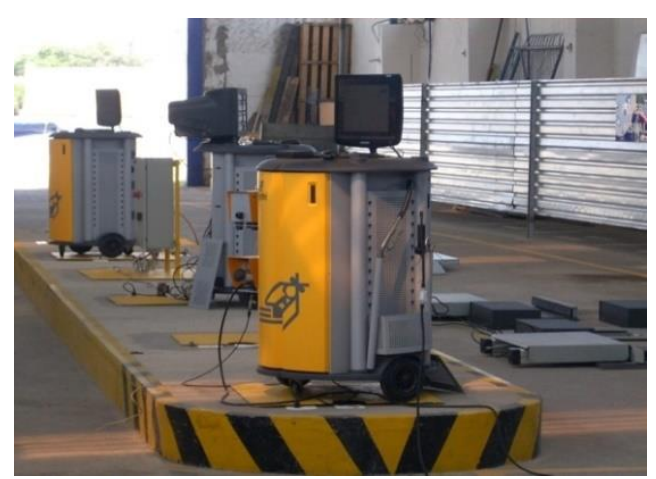

Fig. 2: Gas Analyzer Console.

\section{Results}

\subsection{Results of Periodical Test in Cars}

For the vehicle in study, a Toyota Tercel car, a remarkable reduction of $46,12 \%$ in the emissions of hydrocarbons was obtained after traveling an approximated distance of 5 kilometres after installing the device. A final reduction of 57,30\% was obtained. The car had not fulfilled the norm for hydrocarbons discharges, smaller or equal to $750 \mathrm{ppm}$ but, with the power pack installed, it did.

The first reduction of carbon monoxides was $83 \%$. However, the results for carbon monoxides were affected by the oil burning. A final reduction of $27,71 \%$ was obtained. The norm of emissions in Colombia establishes for carbon monoxides emissions smaller or equal to $4.5 \%$

\subsection{Results of Single Tests for Cars}

Average reductions of $75 \%$ in hydrocarbons were obtained. A remarkable average reduction of $71,73 \%$ in the emissions of the carbon monoxide was obtained. The norm for emissions establishes that the carbon monoxides must have a smaller or equal proportion to the 4,5 percent.

\subsection{Results of Periodical Tests for the first Motorcycle}

Making a constant control of the oil a reduction of $10 \%$ was obtained after traveling a distance of 5 kilometres, after installing the device and a final reduction of $28,65 \%$ was obtained. The norm in Colombia establishes that hydrocarbons emissions must be smaller or equal to $2000 \mathrm{ppm}$ in the motorcycles. The results of the carbon monoxides shown a remarkable change in the reduction, the initial reduction was of the $6,15 \%$ and the end was of the $41,53 \%$.

\subsection{Results of Periodical Tests for the Second Motorcycle}

No oil change was made in this case. Emissions reductions of $20,61 \%$ when installing the device, a raise to a maximum, passing through the other tests, of $82 \%$ and a final decrease to $72 \%$.

The carbon monoxides are the main polluting agent that is affected by the oil burning, the initial reduction was of $4 \%$, an increase to $34 \%$ and finally a decrease to $15,92 \%$.

\subsection{Results of Single Day Tests in Motorcycles}

An average reduction of $74,32 \%$ was obtained for hydrocarbon reduces significantly hydrocarbons just a short time after being installed. The results in motorcycles were far below the norm.

A remarkable average reduction of $75,38 \%$ in the emissions of the carbon monoxide was obtained.

It is Important to state that all the vehicles fulfilled the norms after having the Power Pack ${ }^{\mathrm{TM}}$ installed

\section{Conclusions}

7.1. When the 2 initial emissions tests result for cars were analysed, remarkable reductions of $76 \%$ and $100 \%$ for $\mathrm{HC}$ and $\mathrm{CO}$ respectively were found. For motorcycles, remarkable reductions were $62 \%$ and $70 \%$, respectively, for the gases aforementioned.

7.2. $100 \%$ of the analyzed vehicles fulfill the standard requirements after having the Power Pack TM installed. 
7.3. After installing the Power Pack TM device in the automobiles the hydrocarbons emissions had an average reduction of $75 \%$ and the carbon monoxide emissions an average reduction of $71,73 \%$.

7.4. The average reduction of hydrocarbon emissions in motorcycles was $74,32 \%$ and the carbon monoxide emissions had an average reduction of $75,38 \%$.

Summing up, the dramatic results obtained and because of the lack of a low cost device easily installed into all existing IC engines to effectively enhance fuel efficiency, the РРТМ appears as a promising option to cut gases emissions from mobile sources

\section{References}

[1] F. Camacho, "Evaluación de la reducción de emisiones producidas por automóviles mediante la colocación de dispositivo fuel saver device ORT," Undergraduate student's Thesis, Civil Engineering program, Faculty of Engineering, Universidad de Cartagena, Colombia.

[2] N. Jonassen. (2013, November 1). How Is Static Electricity Generated [Online]. Available: http://incompliancemag.com/article/how-is-static-electricity-generated

[3] Urban platform. (2006, June 10). Las ciudades más contaminadas del mundo [Online]. Available: http://www.plataformaurbana.cl/archive/2006/06/10/las-ciudades-mas-contaminadas-del-mundo/

[4] C. Roatta Acevedo. (2009, March 5). ¿Qué hace Colombia ante el calentamiento global? [Online]. Available: http://warminglobal.blogspot.com.co/2009/03/que-hace-colombia-ante-el-calentamiento.html

[5] G. Anand, The New York Times. (2017, February 14), India's Air Pollution Rivals China's as World's Deadliest [Online]. Available: https://www.nytimes.com/2017/02/14/world/asia/indias-air-pollution-rivals-china-as-worldsdeadliest.html?_r=0

[6] WHO, World Health Organization. (2016, May 12). Air pollution levels rising in many of the world's poorest cities [Online]. Available: http://www.who.int/mediacentre/news/releases/2016/air-pollution-rising/en/

[7] J. Howard, CNN. (2016, September 28). Most of the world breathes polluted air, WHO says [Online]. Available: http://edition.cnn.com/2016/09/27/health/air-pollution-map-who/

[8] WHO, World Health Organization. (2014, March 25). 7 million premature deaths annually linked to air pollution [Online]. Available: http://www.who.int/mediacentre/news/releases/2014/air-pollution/en/

[9] D. Mosbergen, GREEN. (2016, July 1). Air Pollution Kills 6.5 Million People Every Year, And It Could Get Worse Unless We Act Now [Online]. Available: http://www.huffingtonpost.com/entry/air-pollution-deaths-ieareport_us_57762af9e4b0a629c1a97b55

[10] D. Carrington, The Guardian. (2015, September 16). More people die from air pollution than Malaria and HIV/Aids, new study shows [Online]. Available: https://www.theguardian.com/environment/2015/sep/16/more-people-diefrom-air-pollution-than-malaria-and-hivaids-new-study-shows

[11] A. Vaughan, The Guardian. (2015, July 15). Nearly 9,500 people die each year in London because of air pollutionstudy [Online]. Available: https://www.theguardian.com/environment/2015/jul/15/nearly-9500-people-die-eachyear-in-london-because-of-air-pollution-study

[12] The Times of India. (2017, January 11). Air pollution causes 1.2 million deaths in India annually; Delhi most polluted: Greenpeace report [Online]. Available: http://timesofindia.indiatimes.com/india/air-pollution-causes-12lakh-deaths-in-india-annually-delhi-most-polluted-greenpeace-report/articleshow/56478622.cms

[13] A. Vaughan, The Guardian. (2016, September 27). China tops WHO list for deadly outdoor air pollution [Online]. Available: https://www.theguardian.com/environment/2016/sep/27/more-than-million-died-due-air-pollution-chinaone-year

[14] La Voz. (2015, November 30). 11 most polluted cities of Latin America [Online]. Available: http://blog.chron.com/lavoz/2015/11/the-10-most-polluted-cities-of-latin-america/\#photo-715159

[15] Reportero Ambiental. (2009, March 28). La contaminación del aire mata a dos millones de personas cada año [Online]. Available: http://reporteroambiental.blogspot.com.co/2009/03/la-contaminacion-del-aire-matados.html?m=0 